\title{
A new earthquake catalogue for Bulgaria and the conterminous Balkan high hazard region
}

\author{
T. J. Bayliss and P. W. Burton \\ Seismic Risk Group, School of Environmental Sciences, University of East Anglia, Norwich, Norfolk, NR4 7TJ, UK
}

Received: 30 January 2007 - Revised: 13 April 2007 - Accepted: 15 April 2007 - Published: 10 May 2007

\begin{abstract}
A new homogenous earthquake catalogue covering Bulgaria and the surrounding Balkan area has been created with intention of performing a consistent seismic hazard assessment across the region. In keeping with modern requirements of cataloguing seismicity, this catalogue has been made homogenous as far as possible with regards to magnitude, which has been provided on any of four different reported scales for each event; $\mathrm{m}_{b}, \mathrm{M}_{s}, \mathrm{M}_{w}$ and $\mathrm{M}_{L}$. A key historical catalogue for the region has been used to represent the early instrumental period of earthquake recording (1900 to 1963), whilst data have been obtained from the International Seismological Centre (ISC), National Earthquake Information Center (NEIC) and National Observatory of Athens (NOA) to cover the instrumental period of earthquake recording (1964 to 2004). ISC data have also been used to develop a new $\mathrm{m}_{b} \rightarrow \mathrm{M}_{s}$ magnitude conversion equation for the catalogued region. Application of this new magnitude conversion relation, in combination with other selected magnitude scale correlations, ensures reported magnitudes can be systematically rendered onto homogenized $\mathrm{M}_{s}$ and $\mathrm{M}_{w}$ scales for all earthquakes. This catalogue contains 3681 events with homogenized magnitudes $\geq 4.0 \mathrm{M}_{w}$, for the time interval 1900 to 2004 (inclusive), located in the region bounded by $39^{\circ}-45^{\circ} \mathrm{N}, 19^{\circ}-29^{\circ} \mathrm{E}$, at focal depths of $0.0 \mathrm{~km}$ to $401.0 \mathrm{~km}$ and in a magnitude range $4.0 \leq \mathrm{M}_{w} \leq 7.2$. Selected large magnitude $\left(M \geq 6.0 \mathrm{M}_{s}\right)$ earthquakes have had their reported magnitudes reassessed - and adjusted if necessary - in light of work by other authors. Applied statistical approaches aimed at determining the lower threshold to magnitude completeness suggest this catalogue is complete down to a homogenized surface-wave magnitude of $4.6 \mathrm{M}_{s}$.
\end{abstract}

Correspondence to: T. J. Bayliss

(t.bayliss@uea.ac.uk)

\section{Introduction}

Historical earthquake catalogues attempt to represent an area's seismicity as accurately and as completely as possible. The most abundant and accurate information is during the instrumental period, i.e. from the start of the 20th century. Extending further back in time requires access to extensive macroseismic data, early historical records and public reports, and palaeo-seismicity records. An improvement in quality and distribution of seismograph stations over time has enabled a consistent improvement in earthquake data recording. A sharp increase in the numbers of events reported was seen during the 1960's with introduction of the World Wide Seismological Station Network (WWSSN) that provided a reliable and modern global source of recorded earthquake data for researchers to access, and use for many reasons, including creation of earthquake catalogues.

Shebalin et al. (1998) noted that the "... territory of Europe as a whole is not covered by a system of homogenous earthquake catalogues"; Musson (1999) provided support to this claim "... the absence of a reliable, homogenised catalogue for the whole region...". Interest has often been biased towards more seismically active provinces. This is reflected in Bulgarian seismicity not having the same luxury as its more seismically active and consequently better known neighbours in the region, e.g. Greece and Turkey, with regards to the extent to which it has been catalogued in the past. It is often only partially covered or entirely excluded from catalogued areas, and as such seismic risk mitigation will suffer for this. During the second half of the 20th century, a number of authors have taken steps to rectify this shortfall, notably by Shebalin et al. (1974, 1998), Grünthal and Wahlström (2003) and Burton et al. (2004).

This earthquake catalogue and its structure has been governed by seven criteria considered key in developing a robust and suitable tool for seismic hazard assessment. These are born out of limitations with previous attempts in cataloguing

Published by Copernicus GmbH on behalf of the European Geosciences Union. 
Bulgarian and Balkan seismicity, "best practice" principles of earthquake cataloguing and the intended end use of this catalogue. These reasons and criteria are:

1. Currently there exists no catalogue using the best available data that covers the study area;

2. A need to cross political boundaries as earthquake populations don't adhere to them (Alsan et al., 1975; Giardini, 1999; Baba et al., 2000);

3. Catalogues that do cover sections of this study region are often creations of numerous merged data sources (many of which themselves would have been derived in this manner). Creation of an historical earthquake catalogue requires use of several resources to form a tool that is consistent, complete and adheres to specific criteria. However, over zealous use of an excessive number of secondary resources may introduce new and unnecessary problems such as event duplication and inclusion of fake entries (Musson, 1999). The aim here has been to use resources economically and effectively as possible, especially with few resorts to secondary resources;

4. Ultimately, this catalogue is intended to be used in seismic hazard analysis of a specific area, in unison with a second catalogue. Its format is strictly governed by that defined in Burton et al. (2004) to enable tasks outlined in Point 7;

5. Catalogues that are currently best representations of the seismicity of this region (e.g. Kárník, 1968, 1971; Shebalin et al., 1974, 1998; and the British Geological Survey's hypocentre database) are known to possess fake and duplicate entries, have missed events, poorly assigned, or suffer from issues specified above magnitudes (S. Sargeant and R. Musson; personal communication; Shebalin et al., 1998);

6. A desire to make a magnitude homogenous catalogue for the area of study, using carefully selected magnitude conversion equations depending upon the time and area in question;

7. To create a catalogue that is homogenous with the Greek catalogue of Burton et al. (2004) covering the adjacent Greek and Aegean region. This will enable seismic hazard assessments over a wider area of interest, for a longer time interval than is currently possible with any single earthquake catalogue currently available or either catalogue used in isolation, through consolidation of these catalogues.

Therefore, this paper creates a new historical earthquake catalogue for the Balkan region in detail. A description of magnitude conversion equations used, with particular emphasis on conversion from $\mathrm{m}_{b} \rightarrow \mathrm{M}_{s}$ magnitude scales, is provided along with developed region-dependent magnitude conversion hierarchies. A comprehensive assessment of catalogue completeness is also provided. This catalogue will form the main data source for a probabilistic seismic hazard assessment (PSHA) for Bulgaria and the surrounding Balkan region that will be covered in future papers.

\section{Previous catalogues of Balkan seismicity}

Cataloguing of Bulgarian and Balkan seismicity has been attempted before, e.g. Prochazkova, Schenkova and Kárník (1977), Makropoulos (1978), Radu (1979, 1991), Purcaru (1979), Constantinescu and Marza (1980), Makropoulos and Burton (1981), Stanishkova and Slejko (1991), Trifu and Radulian (1991) and Oncescu et al. (1999). Figures 1a and b illustrate the geographical coverage of this catalogue, along with a selection of others described in this section.

Kárník (1968) presented a catalogue for Europe and the Mediterranean region for the time interval 1901 to 1955 consisting of events with macroseismic intensities $\mathrm{I}_{0} \geq \mathrm{VI}$ or magnitudes $\geq 4.5 \mathrm{M}$ as part of the European Seismological Commission's Project of the Seismicity of Europe. It sought to achieve uniform magnitude determinations for the European area (defined approximately as $25^{\circ}-75^{\circ} \mathrm{N}, 30^{\circ} \mathrm{W}-$ $65^{\circ} \mathrm{E}$ ) by applying calibration curves with station and depth corrections. This aimed to provide homogeneity through data in terms of space, time and seismic energy source. Macroseismic epicentres in Bulgaria were given to $1^{\prime}$, representing the centre of the meizoseismal area or the location of $I_{\max }$. Romanian events are given to an accuracy of $0.1^{\circ}$; Turkish events to $0.1^{\circ}$ and $1^{\circ}$; Greece to $1^{\circ}, 1 / 2^{\circ}, 1 / 4^{\circ}$ and $0.1^{\circ}$. The sub-project that provided data for the region of interest, i.e. seismicity of the "Baltic Shield", presented a seismotectonic map for Europe and a study of the seismicity of the Carpathian and Balkan region. Kárník (1971) continued this work, focusing on events with macroseismic intensities $\mathrm{I}_{0} \geq$ VII for the time interval 1801 to 1900 .

The UNDP/UNESCO Survey of the Seismicity of the Balkan Region produced the long respected Shebalin et al. (1974) catalogue. This presents a collection of the main earthquake parameters for Balkan events in the time interval 1901 to 1970 , with $\mathrm{M} \geq 4.0$ or $\mathrm{I}_{0} \geq \mathrm{VI}$. It was accompanied by an Atlas of Isoseismals for key historical earthquakes in the study region. The main sources used to derive its content were listings of Galanopoulos (1960, 1963), Kárník (1968, 1971) and Papazachos and Comninakis (1971).

Alsan et al. (1975) provided the first computerized earthquake catalogue for Turkey, covering the region $35.5^{\circ}$ $42.5^{\circ} \mathrm{N}, 25.5^{\circ}-45^{\circ} \mathrm{E}$ for the period 1913 to 1970 . This pursued the highest possible magnitude homogeneity and completeness through application of $\mathrm{P}$-wave readings from data sources such as the British Association for the Advancement of Science, Bureau Central International de Sèismologie (BCIS), the International Seismological Summary (ISS) and 
(after 1963) the International Seismological Centre (ISC). Earthquake epicentres depended on the Herrin earth model and magnitudes were obtained on a homogenized $\mathrm{M}_{s}$ magnitude scale.

For the Aegean and its surrounding area, extending into southern Bulgaria, Papazachos et al. (1997) developed a strategy to create a new catalogue that could be considered homogenous on the moment magnitude scale. They develop a suite of magnitude conversion relations to allow homogenising of earthquake magnitudes from the other standard magnitude scales, in addition to new empirical relations with macroseismic data of the region. Papazachos et al. found equivalence between $\mathrm{M}$ (magnitude determined from a Wiechert or Mainka seismograph) and $\mathbf{M}_{w}$ when $5.0 \leq \mathrm{M} \leq 8.0$, and also to $\mathrm{M}_{s}$ when $6.0 \leq \mathrm{M} \leq 8.0$. Section 6 outlines how other authors mentioned in this section have found these magnitude equalities to hold similarly for other regions of Europe.

Shebalin et al. (1998) supersedes Shebalin et al. (1974). This earthquake Catalogue for Central and Southeast Europe (CSEE) was compiled within the framework of the RussianGerman project "Reevaluation of the earthquake data for the areas between the EU countries and the territory of the FUSSR (former USSR)". This comprehensive earthquake catalogue covers the time interval $342 \mathrm{BC}$ to 1990 , and $38^{\circ}-$ $55^{\circ} \mathrm{N}, 10^{\circ}-35^{\circ} \mathrm{E}$ for the countries: Poland, Czech Republic, Slovakia, Hungary, Slovenia, Croatia, Bosnia and Herzegovina, Serbia, Montenegro, Macedonia, Albania, Romania and Bulgaria in their entirety as well as western Turkey. Over 50 articles and publications were consulted to enable reporting of magnitudes for 3949 earthquakes in one of four formats: $\mathbf{M}_{s}$ derived from macroseismic and mixed determinations (including estimation from observed maximum intensity, $\mathrm{I}_{\max }$, and depth); $\mathrm{M}_{s}$ derived from direct measurements; $\mathrm{M}_{s}$ converted from SP, LP etc. phases; and $\mathrm{m}_{b}$ derived from direct measurements. Each earthquake was assigned one magnitude estimate, and one epicentral intensity estimate (based on the MSK-64 - Medvedev-Sponheuer-Kárník - scale), with each having an inferred uncertainty attached.

The "southern Balkan area" $33^{\circ}-43^{\circ} \mathrm{N}, 18^{\circ}-30^{\circ} \mathrm{E}$ is covered by Baba et al. (2000) for 1964 to 1995 . They report 60473 shallow-focus events with surface-wave and body-wave magnitude estimates drawn from the ISC and National Earthquake Information Center (NEIC) if available. Additionally, local magnitudes as reported by the Geodynamic Institute of the National Observatory of Athens (NOA), the Geophysics Laboratory of Thessaloniki University (GLAUTH) and the seismological stations of Kandili, Istanbul (ISK), Tirana (TIR), Titograd (TTG) and Skopje (SKO) are cited and used to develop relations between local magnitudes obtained from each station. Scaling relations between reported $\mathrm{M}_{L}$ estimates of local networks and the corresponding seismic moment magnitude were also used to reach magnitude homogeneity in terms of $\mathrm{M}_{w}$.

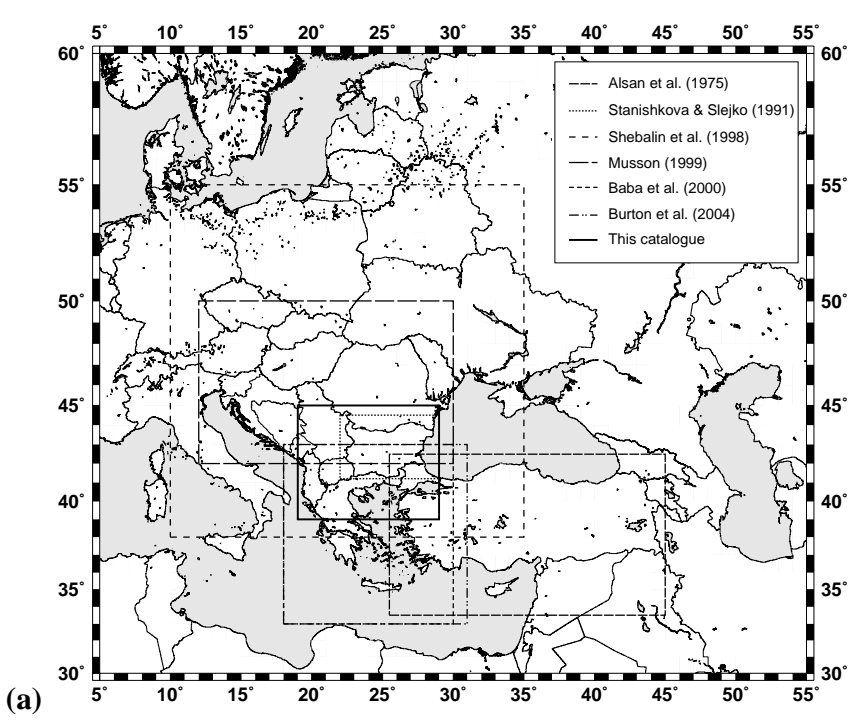

(b)

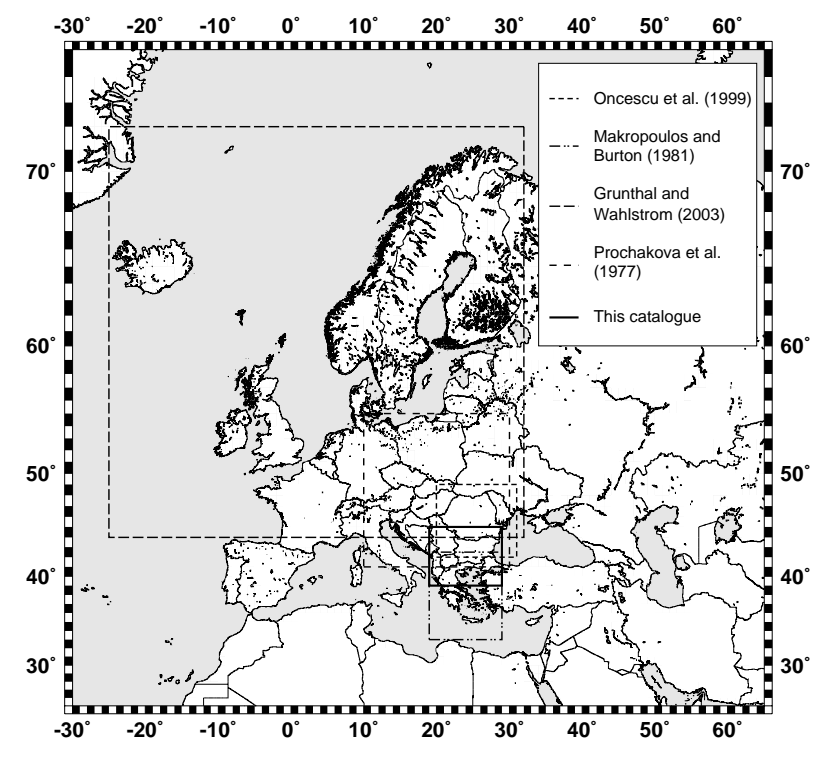

Fig. 1. (a) and (b). Geographical coverage of the catalogue created in this study and those of selected other studies. The geographic extent of (b) represents Kárník $(1968,1971)$. This is irregular in shape, with the limits representative of the latitude and longitude extremes of the region catalogued.

Grünthal and Wahlström (2003) merge 55 individual studies and catalogues to create an $\mathbf{M}_{w}$-based earthquake catalogue for the region bounded by $44^{\circ}-72^{\circ} \mathrm{N}, 25^{\circ} \mathrm{W}-32^{\circ} \mathrm{E}$ (approximately equivalent to GSHAP (Global Seismic Hazard Assessment Program) Region 3; Giardini and Basham, 1993) and time interval 1300 to 1993 . Data on approximately 5000 events is provided, calibrated onto a homogenized $\mathbf{M}_{w}$ magnitude scale through application of a hierarchical conversion system. Values for epicentral intensity, $\mathrm{I}_{0}$, are also provided. This catalogue has a lower magnitude threshold of $3.5 \mathrm{M}_{w}$. 
Burton et al. (2004) extend Makropoulos and Burton's (1981) catalogue with an additional 18 years data from the ISC, NEIC, NOA and Harvard-Centroid Moment Tensor (HRVD-CMT) databases. Magnitude conversion equations from $\mathrm{m}_{b}, \mathrm{M}_{s}, \mathrm{M}_{w}$ and $\mathrm{M}_{L}$ scales onto homogenized $\mathrm{M}_{w}$ and $\mathrm{M}_{s}$, tested to ensure magnitude homogeneity, provide 5198 events during 1900 to 1999 on the homogenized $\mathrm{M}_{s}$ and $\mathrm{M}_{w}$ scales, along with originally reported $\mathrm{m}_{b}, \mathrm{M}_{s}, \mathrm{M}_{w}$ and $\mathrm{M}_{L}$ magnitude estimates. This work provides the template against which the creation of this new regional earthquake catalogue is based.

\section{Data sources}

\subsection{Instrumental period}

The ISC hypocentre database is generally accepted to be the standard source of earthquake location and magnitude data for the instrumental period of definitive recording. The ISC publish revised event locations approximately 24 months after they occur. This allows the greatest possible number of phase readings to be collected for analysis. Typically earthquakes are reported on the body-wave magnitude scale, $\mathrm{m}_{b}$. In addition, surface-wave magnitudes, $\mathbf{M}_{s}$, are often reported, occasionally moment magnitudes, $\mathbf{M}_{w}$, are reported, and rarely local magnitude, $\mathbf{M}_{L}$, and duration magnitude, MD, estimates are reported.

Data were collected from the ISC hypocentre database for the time interval 1964 to 2002 . Only primary hypocentres were selected for those earthquakes located in the region of interest regardless of the agency that computed them. After removing a small number of events with no reported magnitudes, filtering to the study region, and adopting a homogenized magnitude threshold of $4.0 \mathrm{M}_{w}$, ISC data provided 2569 events. Reported magnitudes provided in the catalogue were extracted from the ISC bulletin on a hierarchical basis. If the ISC had computed an estimate (for any magnitude type used) that was selected; if no ISC estimate was available, an estimate of the NEIC were sought; if no NEIC estimate was available, then magnitudes computed by the University of Athens (ATH) were sought. If none of these were available, a magnitude calculated by any other reporting station was accepted. All events are within a magnitude range $4.0 \leq \mathrm{M}_{w} \leq 7.2$, a time interval of 1964 to 2002 and a focal depth range 0.0 to $401.0 \mathrm{~km}$ for the region bounded by $39^{\circ}-$ $45^{\circ} \mathrm{N}, 19^{\circ}-29^{\circ} \mathrm{E}$.

To extend the time interval available, data of the NEIC were acquired for 2003. NEIC report earthquake locations and magnitudes in near real time, and are assigned one of either $\mathrm{M}_{L}, \mathrm{~m}_{b}, \mathrm{M}_{s}, \mathrm{MD}$ or $\mathrm{M}_{w}$ (reported by any one of a number of reporting stations or agencies; e.g. ISK, ATH, IST, BRK, ATU, SKO, TRI, TIR, RMP, GRF). NEIC data provides an additional 61 events in the moment magnitude range $4.0 \leq \mathrm{M}_{w} \leq 5.5$ and focal depth range 0.0 to $72.0 \mathrm{~km}$.
The final year of the catalogue, 2004, is represented by data contributed by NOA. NOA cites earthquakes on the local magnitude scale, $\mathrm{M}_{L}$. NOA provides a further 96 events in the moment magnitude range $4.0 \leq \mathrm{M}_{w} \leq 5.8$ and focal depth range 2.0 to $98.0 \mathrm{~km}$.

\section{Early instrumental period}

Data sources representing the early instrumental period of recording and considered reliable to maintain magnitude homogeneity with the remainder of the instrumental period of seismology were needed. Many sources were considered, including the catalogues of Kárník $(1968,1971)$ and Shebalin et al. (1974), which have since been superseded by Shebalin et al. (1998).

Much emphasis was finally placed upon the catalogue of Shebalin et al. (1998). This catalogue became the sole source of earthquake data for the early instrumental recorded period of seismology, 1900 to 1963 . After filtering events to regional boundaries and to a minimum moment magnitude threshold of $4.0 \mathrm{M}_{w}$, Shebalin et al. (1998) provides an additional 955 events in the homogenized magnitude range $4.0 \leq \mathrm{M}_{w} \leq 7.2$ and focal depth range 0.0 to $160.0 \mathrm{~km}$. Data representing the early instrumental and instrumental periods of recording were not filtered to remove quarry blasts within the catalogued region.

\section{Alterations to reported magnitudes of historical events}

Re-evaluation of magnitude estimates originally reported by seismological agencies is commonplace in earthquake studies with the advent of more data over time. This is particularly true of larger magnitude, destructive events. Similarly, it will often be older events of the early instrumental and historical periods that need re-evaluation due to an initial lack of a comprehensive review of macroseismic and/or instrumental data.

One event for which the magnitude has long been a source of contention, and is of importance here, is the 4 April 1904 Kresna event. This event was reported with a body-wave magnitude estimate of $7.8 \mathrm{~m}_{b}$ by Shebalin et al. (1998), making it the strongest shallow focus earthquake in Europe of the last two centuries (Sledzinski, 2000; Ranguelov et al., $2000 \mathrm{~b}$ ). A lot of research has been undertaken during the latter half of the 20th century focusing upon evaluation of this earthquake's magnitude. Grigorova and Grigorov (1964), Christoskov and Grigorova (1968), Ranguelov et al. (2000a, b; 2001), Rizhikova et al. (2000), Toteva et al. (2000), and Meyer et al. (2007), and references therein, all report on magnitude estimates for this event, the seismic sequence in which it occurred and the seismic potential of the localised KresnaKrupnik seismic zone. Ranguelov et al. (2000b) especially makes effort to highlight how a number of previous studies 
apply alternative methods to appraise this earthquake's magnitude, produce estimates in the range $6.4 \mathrm{M}$ to $7.9 \mathrm{M}$ using neotectonic movements and observed macroseismic intensity estimates respectively.

S. Pavlides has re-evaluated this magnitude to 7.1 to 7.2 $\mathrm{M}_{s}$ (Pavlides and Caputo, 2004; Pavlides, S., personal communication) using historical and fault rupture measurements, following the revision of Ambraseys (2001), Meyer et al. (2002), and Papazachos (1990) and application of empirical formulae from Ambraseys and Jackson (1998) and Wells and Coppersmith (1994). Dineva et al. (2002) estimates this event's surface-wave magnitude as $7.2 \mathrm{M}_{s}$, in agreement with Abe and Noguchi (1983b; after revision from 7.3 $\mathrm{M}_{s}$; Abe and Noguchi, 1983a) and Pacheco and Sykes (1992). Consequently, this new estimate of $7.2 \mathrm{M}_{s}$ is attached to the 1904 Kresna event, in addition to the original body-wave magnitude estimate of Shebalin et al. (1998). These studies intended adjustment of the magnitude of this event (along with other large magnitude early instrumental events that are detailed later) to counter the effect of using undamped narrowband seismometers (Koravos et al., 2003).

To maintain consistency across large magnitude events in this catalogue, additional earthquakes of note were reviewed to determine if their magnitudes had been re-evaluated by past authors. Attention was paid specifically to the early instrumental period, 1900 to 1963 , and events with a reported magnitude of $\mathrm{M} \geq 6.0$ (where $\mathrm{M}$ is a generic reported magnitude scale representing $\mathrm{m}_{b}, \mathrm{M}_{s}, \mathrm{M}_{L}$, and $\mathrm{M}_{w}$ ). The instrumental period (1964 to present) was not reviewed further as this period is covered largely by data of the ISC. A number of studies have re-evaluated ISC data, notably Makropoulos and Burton (1981), Engdahl et al. (1998) and Pérez (1999) in relation to hypocentre locations and teleseismic reporting, completeness and magnitude homogeneity determination. This particular task is considered outside the scope of this study, given that Makropoulos and Burton (1981) obtained small improvements in hypocentre locations (generally $<10 \mathrm{~km}$ ) and Engdahl et al. (1998) achieved similar results for their re-determined hypocentres, suggesting they appeared to be regionally systematic, and possess substantial improvements on focal depth estimates when comparing to other estimates. It was deemed generally acceptable to use ISC hypocentre locations without further analysis.

The events in this catalogue that have been re-evaluated in terms of their magnitude are as follows (along with the newly attached or alternative magnitude estimates):

\subsection{April $1904\left(\right.$ Kresna; $\left.41.7^{\circ} \mathrm{N}, 22.9^{\circ} \mathrm{E}\right) 6.9 \mathrm{M}_{s} / 6.8 \mathrm{M}_{w}$}

Pavlides and Caputo (2004) re-evaluated the main foreshock to the 1904 event. This was re-assigned with a surface-wave magnitude estimate of 6.8 to $6.9 \mathrm{M}_{s}$. Consequently this catalogue reports the $\mathrm{M}_{s}$ magnitude for this event as $6.9 \mathrm{M}_{s}$, in addition to the original estimate by Shebalin et al. (1998) of
$7.1 \mathrm{~m}_{b}$. Dineva et al. (2002) offer a second estimate for this event of $6.8 \mathrm{M}_{w}$ that was also attached.

\subsection{June 1913 (Gorna Orjahovitza; 43.1 ${ }^{\circ} \mathrm{N}, 25.7^{\circ} \mathrm{E}$ ) $6.3 \mathrm{M}_{s}$}

Dineva et al. (2002) discuss the 14th June 1913 Gorna Orjahovitza event. They suggest $6.3 \mathrm{M}_{s}$ as alternative to the estimate of 7.0 $\mathrm{M}_{s}$ proposed by Shebalin et al. (1998). Additionally, Bungum et al. (2003) suggests $6.8 \mathrm{M}_{s}$ as derived by the Pasadena seismological observatory. This revised estimate of $6.3 \mathrm{M}_{s}$ by Dineva et al. (2002) was adopted for this catalogue, as source parameters have been used to derive it, instead of analog and digital records by Bungum et al. (2003).

\subsection{4 and 18 April 1928 (Plovdiv; 42.1 ${ }^{\circ} \mathrm{N}, 25.2^{\circ} \mathrm{E}$ and $\left.42.1^{\circ} \mathrm{N}, 25.0^{\circ} \mathrm{E}\right) 6.7 \mathrm{M}_{w}$ and $7.0 \mathrm{M}_{w}$}

Dimitrov et al. (2004) re-evaluated the Chirpan and Plovdiv events of 14 and 18 April 1928 . These were initially assigned magnitude estimates of $6.8 \mathrm{M}_{s}$ and $7.0 \mathrm{M}_{s}$ respectively by Shebalin et al. (1998). Dimitrov et al. obtain moment magnitude estimates of $6.7 \mathrm{M}_{w}$ and $7.0 \mathrm{M}_{w}$ respectively for these events.

These re-evaluations are used in the catalogue, in addition to retaining magnitude estimates of Shebalin et al. (1998). Also noteworthy is Karakostas et al.'s (2006) attempt to determine slip distribution and fault geometry using surface faulting and deformation. This enabled them to derive alternative and comparable moment magnitude estimates, not attached to this catalogue, of $6.5 \mathrm{M}_{w}$ and $6.9 \mathrm{M}_{w}$ for the Chirpan and Plovdiv events respectively.

In addition to the re-evaluated events discussed above, Bungum et al. (2003) assess a number of events by looking at long-period ground motions for large magnitude European earthquakes of the 20th century. The following events are of note in their work:

\subsection{January $1905\left(42.0^{\circ} \mathrm{N}, 19.5^{\circ} \mathrm{E}\right) 6.6 \mathrm{M}_{s}$}

Assigned 6.6 $\mathrm{M}_{s}$ by Shebalin et al. (1998), Kárník (1971) and Bungum et al. (2003). The magnitude estimate of Shebalin et al. (1998) was retained.

\subsection{January $1906\left(41.1^{\circ} \mathrm{N}, 20.0^{\circ} \mathrm{E}\right) 6.4 \mathrm{M}_{s}$}

This event was assigned surface-wave magnitude estimates of $6.4 \mathrm{M}_{s}$ by Shebalin et al. (1998), and $6.5 \mathrm{M}_{s}$ by Kárník (1971) and Bungum et al. (2003). The magnitude estimate of Shebalin et al. (1998) was adopted.

\subsection{March $1953\left(40.0^{\circ} \mathrm{N}, 27.3^{\circ} \mathrm{E}\right) 7.2 \mathrm{M}_{s}$ and $7.2 \mathrm{M}_{w}$}

This event was not reported by Shebalin et al. (1998) and assigned 7.2 $\mathrm{M}_{s}$ and 7.2 $\mathrm{M}_{w}$ by Pacheco and Sykes (1992). Full 


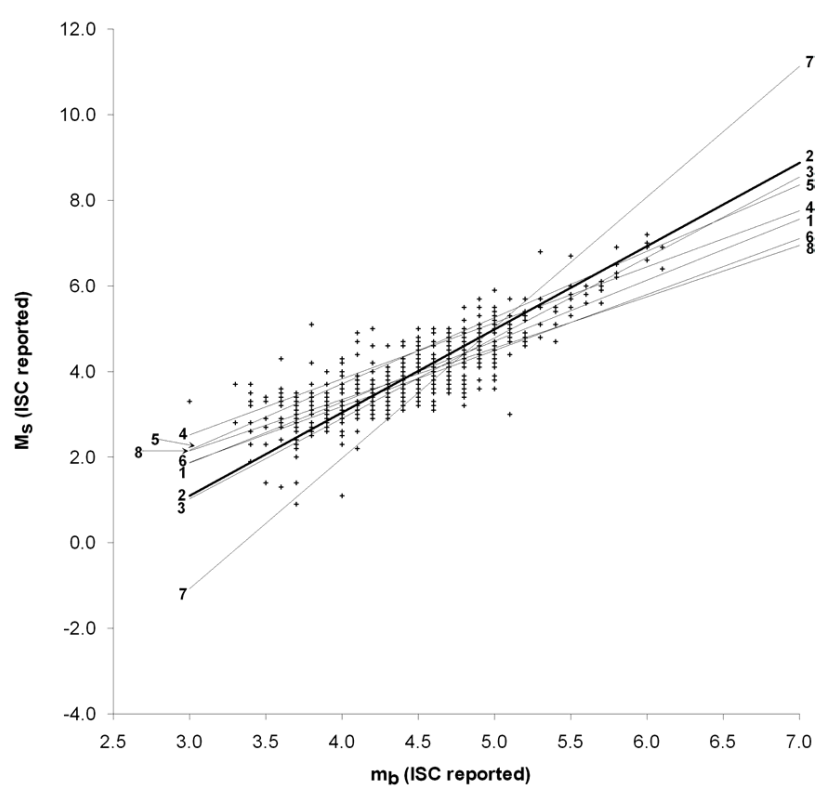

Fig. 2. Selected $\mathrm{m}_{b} \rightarrow \mathrm{M}_{s}$ conversion equations for the region of study. Individual points are 638 ISC events with reported estimates for both $\mathrm{m}_{b}$ and $\mathrm{M}_{s}$ scales. Line 1 - This catalogue (single error); Line 2 - This catalogue (double error); Line 3 - Rezapour and Pearce (47); Line 4 - Makropoulos and Burton (32); Line 5 - Alsan et al. (3); Line 6 - Burton et al. (single error (10)); Line 7 - Burton et al. (double error (10)); Line 8 - Shebalin et al. (50).

event details from Pacheco and Sykes (1992) were adopted; 26 May $1960\left(40.5^{\circ} \mathrm{N}, 20.6^{\circ} \mathrm{E}\right) 6.5 \mathrm{M}_{s}$

Assigned $6.2 \mathrm{M}_{s}$ by Shebalin et al. (1998) and $6.5 \mathrm{M}_{s}$ by Pasadena Seismological Observatory (Bungum et al., 2003). The magnitude estimate of Pasadena Seismological Observatory was adopted.

\section{Homogenous magnitude and magnitude regression conversions}

The International Seismological Centre's (ISC) database provides a rich source of data from which to derive magnitude regression equations. From 1964 the ISC consistently reported $\mathrm{m}_{b}$ magnitude for the majority of earthquakes. Additionally, $\mathrm{M}_{s}$ magnitude is also frequently reported for the same event. Consequently, provided a study region is large enough to contain a reasonable number of events, there is opportunity to develop regression equations between the two principle magnitude scales. This method has been applied a number of times to ISC data (see example regression equations in Table 1) and a good, recent example for global data is provided by Rezapour and Pearce's (1998) result:

$M_{s}=(1.8782 \pm 0.0222) m_{b}-(4.6046 \pm 0.1102)$
The region catalogued has 638 events with paired $\mathrm{M}_{s}$ and $\mathrm{m}_{b}$ ISC magnitude estimates. Regressing $\mathbf{M}_{s}$ values on $\mathrm{m}_{b}$ for these earthquakes results in Eqs. (2) and (3) using standard single and York (1969) double-error regression techniques respectively;

$$
\begin{aligned}
& M_{s}=1.4311( \pm 0.040) m_{b}-2.4394( \pm 0.178) \\
& M_{s}=1.9418( \pm 0.0443) m_{b}-4.7256( \pm 0.2002)
\end{aligned}
$$

Single error regression assumes uncertainty only in data of the y-axis variable. York (1969) presented reasoning for the least squares quadratic to be used in generalised forms when it is found that errors in the y-coordinate of a given point is correlated to errors in the $\mathrm{x}$-coordinate through the data range. Figure 2 plots the 638 events with both $\mathrm{m}_{b}$ and $\mathrm{M}_{s}$ magnitude estimated by the ISC for the study area with the $\mathrm{m}_{b} \rightarrow \mathrm{M}_{s}$ conversion equations of Table 1 .

Clearly, many alternative magnitude scale conversions for the region have been proposed and this is inevitably an ongoing situation as more, and better data accumulate. Although the $\mathrm{M}_{s} / \mathrm{m}_{b}$ pairing is vital, other scale conversions are required to finish this catalogue. Conversion equations to be used here are governed by five key points:

1. The existence of a "common" area $39^{\circ}-43^{\circ} \mathrm{N}, 19^{\circ}$ $29^{\circ} \mathrm{E}$ overlapping the catalogued region of Burton et al. (2004), and the equations used for equivalent conversions in that work;

2. Whether the sub-region is north or south of $43^{\circ} \mathrm{N}$ (the boundary between the area "common" with Burton et al. (2004) and that which is not);

3. The magnitude type;

4. The magnitude scale conversion required;

5. Conversion equations used in previous studies.

Equations used to render each earthquake in this catalogue onto the required magnitude scales for the region south of $43^{\circ} \mathrm{N}$ are set as those used in Burton et al. (2004), and these are summarised in Tables $2 \mathrm{a}$ and $\mathrm{b}$. These aim to maintain magnitude homogeneity between this catalogue, Burton et al's Greek catalogue, and the $\mathrm{M}_{s}$ re-evaluation performed for the Makropoulos and Burton (1981) catalogue. Tables 2a and $\mathrm{b}$ provide the further conversion equations between $\mathrm{M}_{w}$ and $\mathbf{M}_{s}, \mathbf{M}_{w}$ and $\mathrm{M}_{L}$ and $\mathrm{M}_{w}$ and $\mathrm{m}_{b}$ that apply south of $43^{\circ} \mathrm{N}$.

The region north of $43^{\circ} \mathrm{N}$ requires detailed homogenizing for the purpose of this study. This region is dominated geographically not only by northern Bulgaria, but also by southern Romania and Yugoslavia, and as such, conversion equations derived in previous studies of seismicity for them are of interest here, as are regressions that can now be determined from data within the catalogue itself. Grünthal and Wahlström (2003) and Bungum et al. (2003) find the equality 
Table 1. $\mathrm{m}_{b} \rightarrow \mathrm{M}_{s}$ magnitude conversion relations of note to this work.

\begin{tabular}{|c|c|c|}
\hline Equation & Comment & Reference \\
\hline $\mathrm{M}_{s}=1.59 \mathrm{~m}_{b}-3.97$ & & Gutenberg and Richter (1949) \\
\hline $\mathrm{M}_{s}=1.55 \mathrm{~m}_{b}-2.49$ & $\begin{array}{l}110 \text { events with ISC } \mathrm{m}_{b} \text { and } \mathrm{M}_{s} \text { magnitude estimates } \\
\text { covering region of Turkey. }\end{array}$ & Alsan et al. (1975) \\
\hline $\mathrm{M}_{s}=1.31 \mathrm{~m}_{b}-1.41$ & $\begin{array}{l}\text { Obtained using ISC data for } 126 \text { earthquakes for the } \\
\text { time interval } 1964 \text { to } 1975 \text { (standard deviation of } \\
0.41 \text { ). }\end{array}$ & Makropoulos and Burton (1981) \\
\hline $0.86 \mathrm{mb}-0.49 \mathrm{Ms}=1.94$ & $\begin{array}{l}\text { Obtained using re-evaluated events with } 3.0 \leq \mathrm{M} \leq 8.0 \\
\text { to derive orthogonal regression relationships between } \\
\mathrm{mb}, \mathrm{mB}, \mathrm{Ml} \text { and } \mathrm{Ms} \text {. }\end{array}$ & Ambraseys (1990) \\
\hline $\mathrm{M}_{s}=(1.8782 \pm 0.0222) \mathrm{m}_{b}-(4.6046 \pm 0.1102)$ & $\begin{array}{l}\text { Used global data for } 13903 \text { earthquakes with ISC } \\
\text { data. }\end{array}$ & Rezapour and Pearce (1998) \\
\hline $\mathrm{M}_{s}=1.2 \mathrm{~m}_{b}-1.45$ & $\begin{array}{l}\text { ISC data with paired } \mathrm{m}_{b} \text { and } \mathrm{M}_{s} \text { magnitude estimates } \\
\text { used. }\end{array}$ & Shebalin et al. (1998) \\
\hline $\mathrm{M}_{s}=1.306( \pm 0.070) \mathrm{m}_{b}-2.037( \pm 0.32)$ & $\begin{array}{l}591 \text { events with both ISC } \mathrm{m}_{b} \text { and } \mathrm{M}_{s} \text { estimates using } \\
\text { single-error regression }\end{array}$ & Burton et al. (2004) \\
\hline $\mathrm{M}_{s}=3.05( \pm 0.10) \mathrm{m}_{b}-10.22( \pm 0.47)$ & $\begin{array}{l}\text { As above, but using a York (1969) double-error re- } \\
\text { gression method. }\end{array}$ & Burton et al. (2004) \\
\hline
\end{tabular}

$\mathrm{M}_{w}=\mathrm{M}_{s}$ holds for central and northern Europe. Oncescu et al. (1999) also adopt this equality.

The simple equality between $\mathrm{M}_{w}$ and $\mathrm{M}_{s}$ is not shared by other magnitude scale pairs, and the importance of adopting appropriate magnitude conversion hierarchies in developing earthquake catalogues is paramount (e.g. Alsan et al. (1975), Oncescu et al. (1999), Grünthal and Wahlström (2003) and Burton et al. (2004) all use such strategies to enable an homogenous magnitude scale). A magnitude conversion hierarchy was necessary in the development of the GSHAP Project (Basham and Giardini, 1993; Johnston and Halchuk, 1993). Magnitude conversion hierarchies are important as they enable homogenizing a catalogue onto a specific magnitude scale and counteract inhomogeneity resulting from merging multiple catalogues that may represent two different political, geographical or seismotectonic regions, effectively removing the existence of any divide in question.

Thus for the region north of $43^{\circ} \mathrm{N}$ conversions to $\mathrm{M}_{w}$ and $\mathbf{M}_{s}$ are facilitated by the equations of Tables $2 \mathrm{c}$ and $\mathrm{d}$ while the vital link between $\mathrm{m}_{b}$ and $\mathrm{M}_{s}$ is provided by Eq. (3) from this study. Hierarchies used to develop this catalogue were then both aided and constrained by the requirement for it to be systematically consistent with, and expand upon, the catalogue of Burton et al. (2004). Further detailed investigation of seismic hazard around the southwest political triple junction between Bulgaria, Greece and Macedonia was also a strong factor in its creation. Consequently, final strategies adopted for conversion onto homogenized moment magnitude, $\mathbf{M}_{w}$, and surface-wave magnitude, $\mathbf{M}_{s}$, scales respectively are given below; Tables $2 \mathrm{a}$ and $\mathrm{b}$ represent hierarchies of a magnitude conversion selection for the region south of and including $43^{\circ} \mathrm{N}$ and Tables $2 \mathrm{c}$ and $\mathrm{d}$ represent the region north of $43^{\circ} \mathrm{N}$.

Figures $3 \mathrm{a}$ and $\mathrm{b}$ illustrate the final content of this catalogue in terms of epicentral location and event magnitude.
Figure 3a illustrates all 3681 events contained in the catalogue. Figure $3 \mathrm{~b}$ illustrates the 334 events with homogenized magnitude $\geq 5.0 \mathrm{M}_{s}$.

\section{Catalogue completeness}

A key requirement of any historical earthquake catalogue is to be as complete and homogenous as possible with respect to magnitude, intensity or other accepted earthquake parameter; certainly down to a known threshold for a known time span. A number of methods exist that analyse catalogue completeness. Data completeness and homogeneity is largely dependent upon availability and is governed by factors including the time interval in question, geographical region, and recording instrumentation used. It is fair to assume that with time, data availability will improve in most regions given implementation of superior monitoring methods.

The catalogue was truncated at a moment magnitude of $4.0 \mathrm{M}_{w}$ in order to include as many small well-determined events as possible and thereby provide the best representation of the seismicity. Truncation at $4.0 \mathrm{M}_{w}$ rather than $4.0 \mathrm{M}_{s}$ was done because the latter would remove a significant number of smaller events $\left(4.0 \mathrm{M}_{w} \cong 2.4 \mathrm{M}_{s}\right.$ whereas $4.0 \mathrm{M}_{s} \cong 4.9 \mathrm{M}_{w}$; Burton et al., 2004)

Catalogue completeness is defined as the magnitude above which it is considered to be fully reported. The traditional method for estimating completeness of a catalogue uses the cumulative frequency-magnitude distribution of Gutenberg and Richter (1944) and Richter (1958). For the purposes of this paper, magnitude completeness will be examined using: the cumulative frequency-magnitude distribution and a timemagnitude distribution. 
Table 2a. Hierarchical strategy adopted for converting onto the moment magnitude scale, $\mathbf{M}_{w}$, south of $43^{\circ} \mathrm{N}$. Relations are used in decreasing order of preference as one reads down the table, and dependent upon reported magnitude types.

\begin{tabular}{llll}
\hline From & Comments & Conversion equation & Source \\
\hline $\mathrm{M}_{w}$ & & $\mathrm{M}_{w}$ & \\
$\mathrm{M}_{s}$ & If $\mathrm{M}_{s}<5.3$ & $\mathrm{M}_{w}=0.56 \mathrm{M}_{s}+2.66$ & Papazachos and Papazachou (1997), \\
& If $\mathrm{M}_{s} \geq 5.3$ & $\mathrm{M}_{w}=0.804 \mathrm{M}_{s}+1.28$ & Burton et al. (2004) \\
$\mathrm{m}_{b}$ & $4.8 \leq \mathrm{m}_{b} \leq 6.0$ & $\mathrm{M}_{w}=1.28 \mathrm{~m}_{b}-1.12$ & Papazachos and Papazachou (1997), \\
& & & Papazachos et al. (1997) \\
$\mathrm{M}_{L}$ & & $\mathrm{M}_{w}=\mathrm{M}_{L}+0.43$ & Baba et al. (2000) \\
\hline
\end{tabular}

Table 2b. Hierarchical strategy adopted for converting onto the surface-wave magnitude scale, $\mathrm{M}_{s}$, south of $43^{\circ} \mathrm{N}$. Relations are used in decreasing order of preference as one reads down the table, and dependent upon reported magnitude types.

\begin{tabular}{llll}
\hline From & Comments & Conversion equation & Source \\
\hline $\mathrm{M}_{s}$ & & $\mathrm{M}_{s}$ & \\
$\mathrm{M}_{w}$ & If $\mathrm{M}_{s}<5.3$ & $\mathrm{M}_{w}=0.56 \mathrm{M}_{s}+2.66$ & Papazachos and Papazachou (1997), \\
& If $\mathrm{M}_{s} \geq 5.3$ & $\mathrm{M}_{w}=0.804 \mathrm{M}_{s}+1.28$ & Burton et al. (2004) \\
$\mathrm{m}_{b}$ & & $\mathrm{M}_{s}=(1.8782 \pm 0.0222) \mathrm{m}_{b}-(4.6046 \pm 0.1102)$ & Rezapour and Pearce (1998) \\
$\mathrm{M}_{L}$ & $\mathrm{M}_{L}(\mathrm{ATH})$ is the lo- & $\mathrm{M}_{s}=1.70( \pm 0.05) \mathrm{M}_{\mathrm{L}(\mathrm{ATH})-3.59( \pm 0.22)}$ & Burton et al. (1991) \\
& cal magnitude scale as & & \\
& recorded at the NOA. & & \\
\hline
\end{tabular}

\section{Cumulative frequency-magnitude distribution}

The commonest method for assessing magnitude distribution and completeness of an earthquake catalogue uses the Gutenberg-Richter cumulative frequency-magnitude law (i.e. $\log \mathrm{N}_{c}(\mathrm{~m})=\mathrm{a}-\mathrm{bm}$, where $\mathrm{N}_{c}(\mathrm{~m})$ counts the number of earthquakes with magnitude greater than or equal to magnitude $\mathrm{m}$, and $\mathrm{a}$ and $\mathrm{b}$ are seismicity and zone-dependent constants). The data are presented in Fig. 4 for magnitudes $\geq 4.0 \mathrm{M}_{s}$ on the catalogue's homogenized $\mathrm{M}_{s}$ scale. Periods considered are: the full catalogue (1900 to 2004); early instrumental (1900 to 1963) and modern instrumental (1964 to 2004).

Viewing catalogue content in this manner suggests a completeness threshold of about $4.6 \mathrm{M}_{s}$ for the full catalogue data. This is the magnitude at which the straight line deviates from linearity towards smaller magnitudes and it is indicated by the solid vertical line. Additional lines on Fig. 4 denote the gradient and b-values for the catalogue time intervals: early instrumental, modern instrumental and the full catalogue. These b-values for each section of the catalogue are an important measure of regional activity (Utsu, 1971; Vere-Jones, 1970). Data representing the full time interval, 1900 to 2004 , and with magnitudes $\geq 4.6 \mathrm{M}_{s}$, has an avalue of $4.62( \pm 0.18)$ and $b$-value of $0.820( \pm 0.03$; by least squares). Lower b-values may correspond to time intervals or geographic regions relatively dominated by larger earth- quakes (e.g. Yilmaztürk et al., 1998; Yilmaztürk and Burton, 1999). The $b$-value for the early instrumental period is $0.760( \pm 0.02$; a-value $=4.28 \pm 0.09)$, and this is the period of the large magnitude 1904 Kresna-Kroupnik, 1928 Plovdiv, and 1913 Gorna Orjahovitza earthquakes. However, a similar b-value of $0.790( \pm 0.02$; a-value $=4.45 \pm 0.15)$ is returned for the modern instrumental period. These estimates show good agreement with other studies, falling in the middle of the range from Alsan et al. (1975), Christoskov (1982), Sokerova et al. (1992), van Eck and Stoyanov (1996) and Musson (1999), who obtain b-values from 0.550 to 1.155 . Both outliers are from Musson (1999), otherwise b-values are 0.66 to 0.90 .

A magnitude-density (frequency) distribution provides an additional means by which to estimate the lower level of completeness of an earthquake catalogue. van Eck and Stoyanov (1996) use this method on their homogenized catalogue for southern Bulgaria, and Willemann (1999) takes advantage to analyse completeness of International Seismological Centre Bulletin data for 1995 compared to 1994 for a number of global seismic regions. Willemann suggests that, where several hundred magnitude estimates are available, an objective estimate for the lower bound of data completeness is indicated by the maximum of the density distribution. The inset to Fig. 4 provides the density distribution for all the data of this catalogue with homogenized magnitude $\geq 2.4 \mathrm{M}_{s}$. Using the above assumption a completeness threshold of $2.9 \mathrm{M}_{s}$ 
Table 2c. Hierarchical strategy adopted for converting onto the moment magnitude scale, $\mathbf{M}_{w}$, north of $43^{\circ} \mathrm{N}$. Relations are used in decreasing order of preference as one reads down the table, and dependent upon reported magnitude types.

\begin{tabular}{llll}
\hline From & Comments & Conversion equation & Source \\
\hline $\mathrm{M}_{w}$ & $\mathrm{M}_{w}$ & \\
$\mathrm{M}_{s}$ & $\mathrm{M}_{w}=\mathrm{M}_{s}$ & $\begin{array}{l}\text { Oncescu et al. (1999), } \\
\text { Grünthal and Wahlström (2003) }\end{array}$ \\
$\mathrm{m}_{b} \quad 4.8 \leq \mathrm{m}_{b} \leq 6.0$ & $\mathrm{M}_{w}=1.28 \mathrm{~m}_{b}-1.12$ & $\begin{array}{l}\text { Papazachos and Papazachou (1997), } \\
\text { Papazachos et al. (1997) }\end{array}$ \\
$\mathrm{M}_{L}$ & & $\mathrm{M}_{w}=\mathrm{M}_{L}+0.43$ & Baba et al. (2000) \\
\hline
\end{tabular}

Table 2d. Hierarchical strategy adopted for converting onto the surface-wave magnitude scale, $\mathrm{M}_{s}$, north of $43^{\circ} \mathrm{N}$. Relations are used in decreasing order of preference as one reads down the table, and dependent upon reported magnitude types.

\begin{tabular}{llll}
\hline From & Comments & Conversion equation & Source \\
\hline $\mathrm{M}_{s}$ & & $\mathrm{M}_{s}$ & \\
$\mathrm{M}_{w}$ & If $\mathrm{M}_{s}<5.3$ & $\mathrm{M}_{w}=0.56 \mathrm{M}_{s}+2.66$ & Papazachos and Papazachou (1997), \\
& If $\mathrm{M}_{s} \geq 5.3$ & $\mathrm{M}_{w}=0.804 \mathrm{M}_{s}+1.28$ & Burton et al. (2004) \\
$\mathrm{m}_{b}$ & $\mathrm{M}_{s}=1.9418( \pm 0.0443) \mathrm{m}_{b}-4.7256( \pm 0.2002)$ & This work \\
$\mathrm{M}_{L}$ & $\begin{array}{l}\mathrm{M}_{L}(\mathrm{ATH}) \text { is the lo- } \\
\text { cal magnitude scale as }\end{array}$ & $\mathrm{M}_{s}=1.70( \pm 0.05) \mathrm{M}_{L}(\mathrm{ATH})-3.59( \pm 0.22)$ & Burton et al. (1991) \\
& $\begin{array}{l}\text { recorded at the NOA. } \\
\end{array}$ & \\
\hline
\end{tabular}

might be intimated. However, this is clearly far too low to suggest with any real confidence, and a completeness threshold of $4.6 \mathrm{M}_{s}$ is adopted as a conservative estimate from Fig. 4. It is worth noting, however, that altering any of the magnitude estimates attached to larger earthquakes present in this catalogue, may further improve the correlations and accuracy of Figs. 2 and 4 (B. Ranguelov, personal communication).

\subsection{Time-magnitude distribution}

The numbers of earthquakes reported in the catalogue per decade are shown in Fig. 5 for specific magnitude intervals. Table 3 provides the values used to create the time-magnitude distribution plot and provides a synopsis of catalogue content. Events have been classified into six magnitude intervals: $\mathrm{M}_{s} \leq 4.0,4.0 \leq \mathrm{M}_{s}<4.5,4.5 \leq \mathrm{M}_{s}<5.0,5.0 \leq \mathrm{M}_{s}<5.5$, $5.5 \leq \mathrm{M}_{s}<6.0$ and $\mathrm{M}_{s} \geq 6.0$. Figure 5 suggests that all events in magnitude interval $4.5 \leq \mathrm{M}_{s}<5.0$ have been reported back to the decade 1930 to 1939 , and events in magnitude interval $5.0 \leq \mathrm{M}_{s}<5.5$ are fully reported throughout the catalogue time span. A gradual fluctuation in the numbers reported at this magnitude interval (i.e. $5.0 \leq \mathrm{M}_{s}<5.5$ ) suggests timevarying seismicity might be occurring during the period of the catalogue. Two distinct peaks are seen at 1920 to 1929 and 1980 to 1989 , suggesting periodicity of about 50 to 60 years for events of these magnitudes. The magnitude interval $4.5 \leq \mathrm{M}_{s}<5.0$ exhibits similar fluctuations across the full time interval suggesting a shorter periodicity for events in this magnitude interval to that suggested for the interval $5.0 \leq \mathrm{M}_{s}<5.5$. A gradual decrease in the number of events reported for magnitudes with $\mathrm{M} \geq 5.5$ over the full time interval suggests this may be only a section of a longer period of time-varying seismicity for this magnitude interval, i.e. longer than the full length of the catalogue.

Significant increases in the total number of reported events in the decade 1960 to 1969 and thereafter simply reflect the introduction of the WWSSN, and the proliferation of seismological data globally. Since then, numbers of smaller magnitude earthquakes with magnitudes of $\leq 4.0 \mathrm{M}_{s}$ reported have increased significantly, due to an increase in sensitivity of recording stations, number of recording stations accessible and geographical coverage of seismological stations improving. A progressive expansion of the Bulgarian seismograph monitoring network was seen from the 1960s to 1980s; this is reflected in the increased number of magnitude $\leq 4.5 \mathrm{M}_{s}$ events reported per decade. The 1960s and 1970s saw Bulgaria's network expand using three-component seismometers to encompass more of the seismogenic zones in the country (Glavcheva et al., 2003). A further expansion of the network was seen in the mid-1980s after the 1977 Vrancea earthquake sequence. This significant increase in numbers of events reported with magnitude $<4.5 \mathrm{M}_{s}$ after 1960 suggests that reporting of these events would be severely incomplete before this time. The use of the expanded network of seismometers 


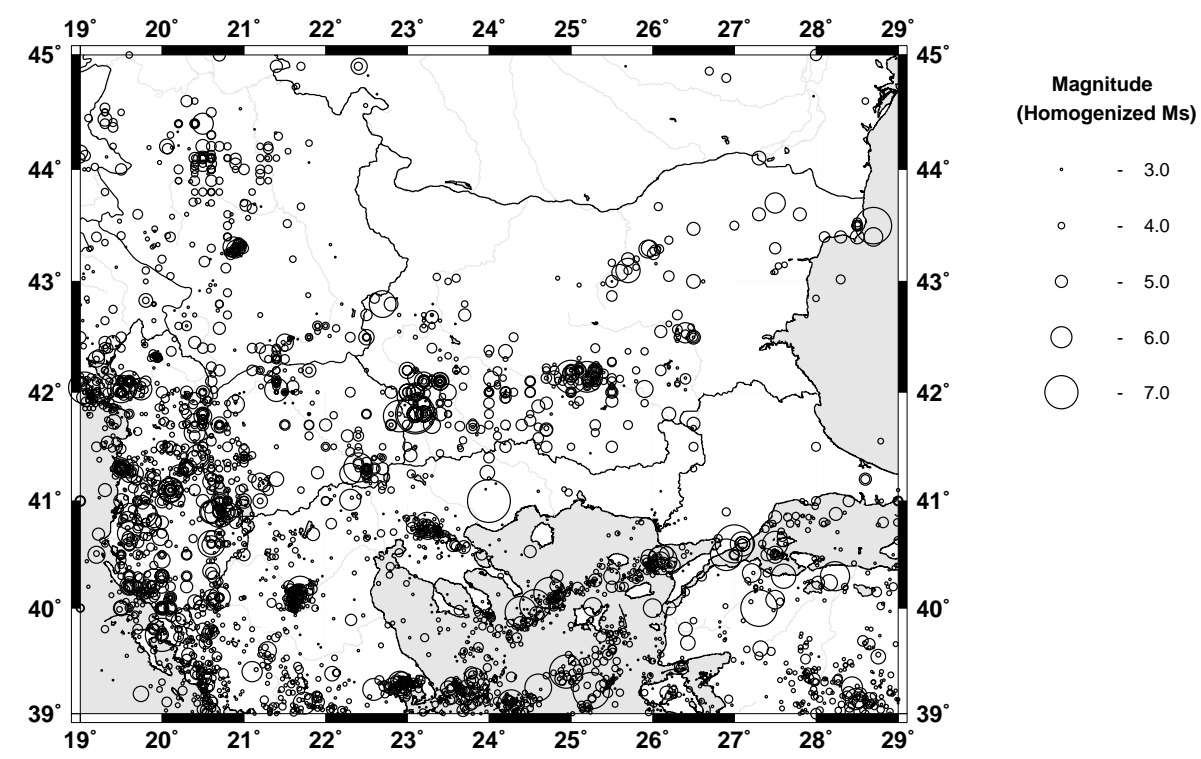

Fig. 3a. Earthquake epicentres in the Balkan and south eastern European region for all events, represented by the 3681 events listed in the presented catalogue (i.e. all magnitudes and focal depths).

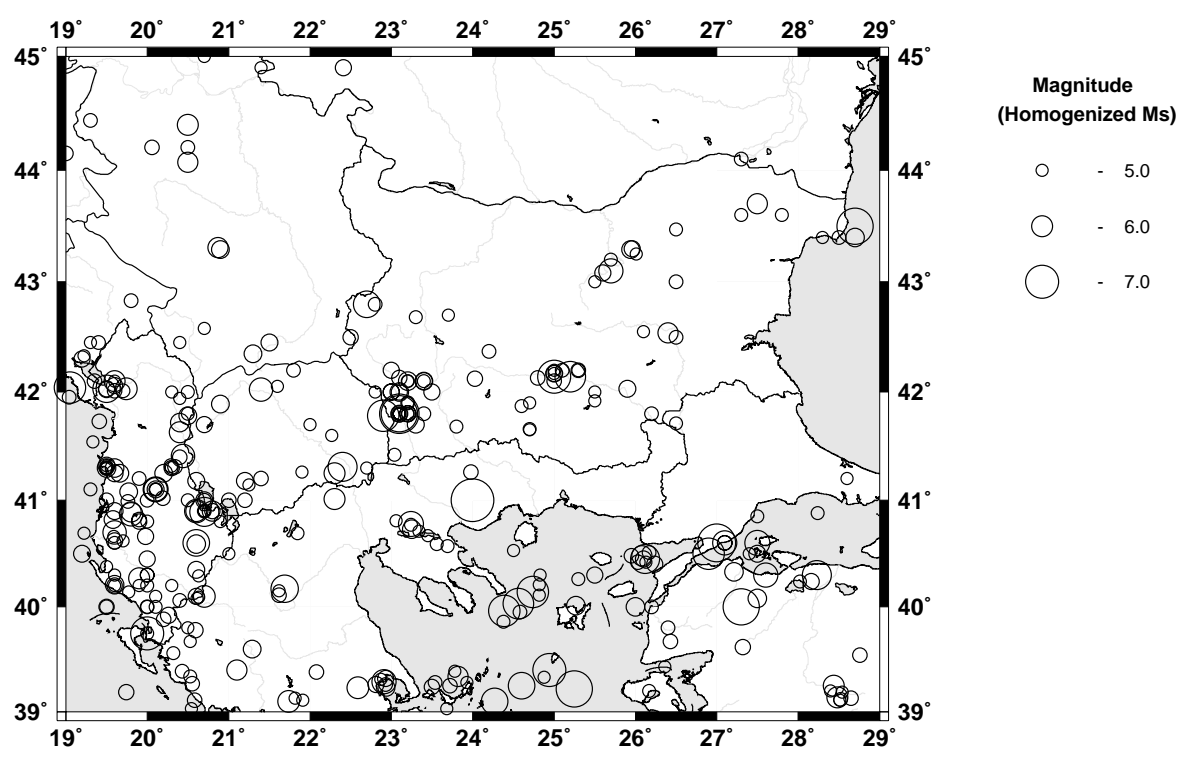

Fig. 3b. Epicentres in Bulgaria and the surrounding Balkan region with homogenized magnitude $\mathrm{M}_{s} \geq 5.0$ and all focal depths.

within Bulgaria obviously has an effect on the threshold of magnitude completeness able to be reported. Finally, it is worth noting that the ISS started receiving data from Sofia, Bulgaria in December 1952. However, data provision was very infrequent (amounting to a few deliveries in 1952 and 1964) until continuous supply commenced in January 1991 until the present day. To compensate for this, estimates of earthquake hypocentres were derived from other agencies contributing phase data at the time.

\section{Catalogue format}

The format of this catalogue in its readily available form is as follows.

YEAR (F4.0), MONTH (F3.0), DATE (F3.0), HOUR (F4.0), MINUTE (F3.0), SECOND (F7.2), LATITUDE (F8.2), LONGITUDE (F8.2), DEPTH (F7.1), HOMOGENIZED_MW (F8.1), HOMOGENIZED_MS (F8.1), MB_REPORTED (F8.1), MS_REPORTED (F8.1), MW_REPORTED (F8.1), ML_REPORTED (F8.1) 


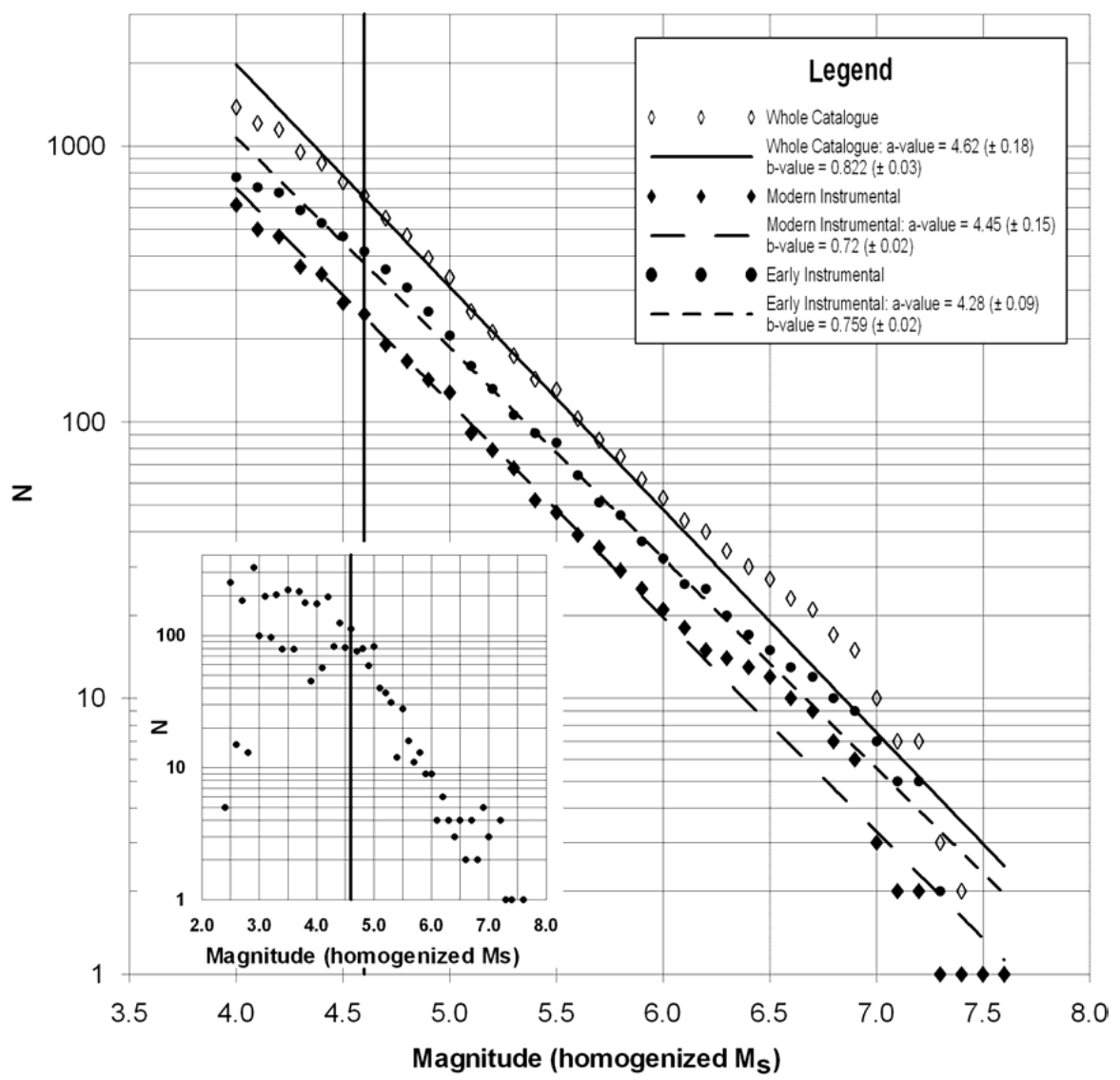

Fig. 4. Catalogue completeness: Gutenberg-Richter cumulative frequency-magnitude plot. Solid triangles represent the full catalogue (1900 to 2004 inc.), clear diamonds represent the early instrumental period of earthquake recording (1900 to 1963 inclusive) and solid circles represent the instrumental period of earthquake recording (1964 to 2004 inclusive.) Data are shown for (homogenized) magnitudes $\geq 4.0 \mathrm{M}_{S}$. Inset depicts the magnitude-density distribution of the catalogue. Solid lines are at $4.6 \mathrm{M}_{s}$ on both main plot and inset, that is, the suggested threshold of completeness for this catalogue.

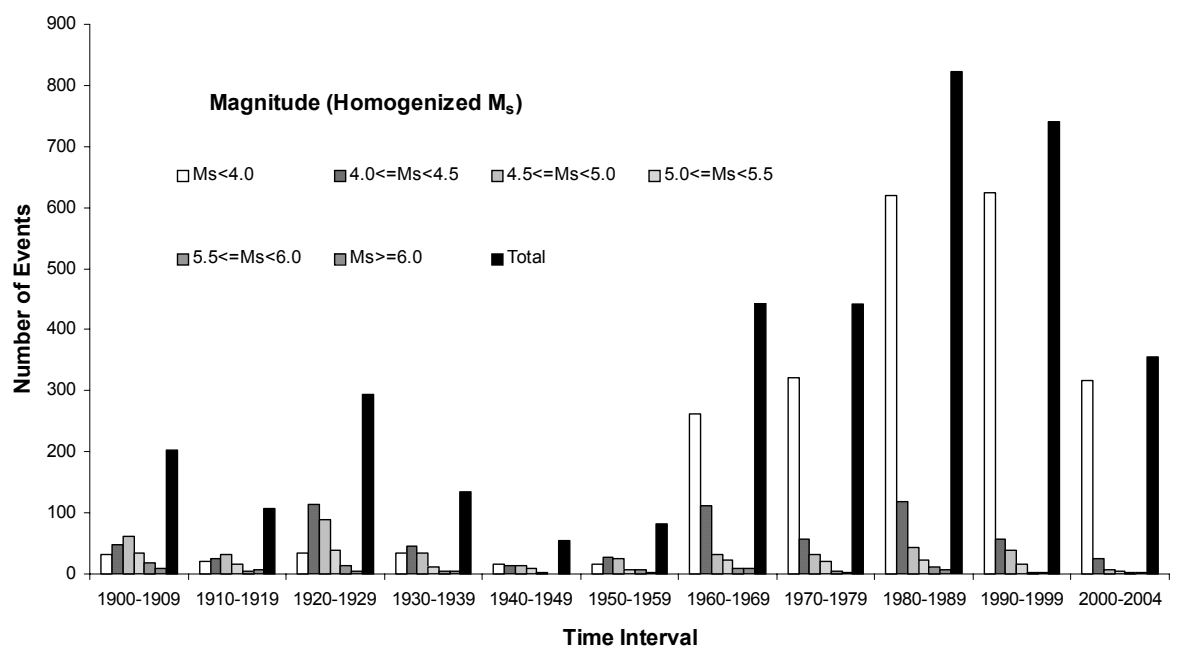

Fig. 5. Catalogue completeness: the catalogue in discrete magnitude and time intervals. All data are represented (i.e. 1900 to 2004 , homogenized $\left.\mathrm{M}_{s} \geq 2.4\right)$. 
Table 3. Time-Magnitude distribution for the catalogue. The number of events is given in discrete magnitude intervals of $0.5 \mathrm{M}_{s}$, and for time intervals of 10 years (except for the final time interval which is 5 years) and is presented in Fig. 2.

\begin{tabular}{llllllll}
\hline Period & $\mathrm{M}_{s} \leq 4.0$ & $4.0 \leq \mathrm{M}_{s}<4.5$ & $4.5 \leq \mathrm{M}_{s}<5.0$ & $5.0 \leq \mathrm{M}_{s}<5.5$ & $5.5 \leq \mathrm{M}_{s}<6.0$ & $\mathrm{M}_{s} \geq 6.0$ & Total \\
\hline $1900-1909$ & 31 & 47 & 61 & 35 & 19 & 10 & 203 \\
$1910-1919$ & 20 & 25 & 32 & 17 & 5 & 7 & 106 \\
$1920-1929$ & 35 & 113 & 90 & 38 & 14 & 5 & 295 \\
$1930-1939$ & 35 & 45 & 34 & 12 & 5 & 4 & 135 \\
$1940-1949$ & 15 & 14 & 14 & 9 & 2 & 1 & 55 \\
$1950-1959$ & 16 & 28 & 24 & 7 & 6 & 2 & 83 \\
$1960-1969$ & 262 & 111 & 31 & 23 & 8 & 10 & 445 \\
$1970-1979$ & 322 & 58 & 33 & 21 & 4 & 3 & 441 \\
$1980-1989$ & 620 & 118 & 44 & 22 & 11 & 7 & 822 \\
$1990-1999$ & 625 & 58 & 38 & 15 & 2 & 2 & 740 \\
$2000-2004$ & 317 & 24 & 7 & 4 & 2 & 2 & 356 \\
\hline Total & 2298 & 641 & 408 & 203 & 78 & 53 & 3681 \\
\hline
\end{tabular}

HOMOGENIZED_MW and HOMOGENIZED_MS are moment and surface-wave magnitude scales calculated from the reported $\mathrm{m}_{b}, \mathrm{M}_{s}, \mathrm{M}_{w}$ and $\mathrm{M}_{L}$ magnitude estimates using the magnitude conversion equations and magnitude conversion hierarchies specified in Sect. 6.

Provision of homogenized magnitude estimates on both moment and surface-wave scales for each event is done for several reasons. First, it maintains a need for consistency between the Greek catalogue and this catalogue; second, to enable hazard calculations consistent with past studies in the magnitude scale and types used. Third, providing the moment magnitude estimates will allow a globally uniform overview of seismicity. The second point concerning which magnitude scale(s) to provide and use for calculations, is still under discussion. Grünthal and Wahlström (2003) state "Seismic hazard calculations are currently based mostly on $\mathbf{M}_{w}$ magnitudes, which, unlike other magnitude concepts, do not saturate for strong events. Most strong motion relations refer to $\mathbf{M}_{w}$ ". Their work was strongly based around the Global Seismic Hazard Assessment Program (GSHAP) which itself was based heavily on use of the seismic moment, $\mathbf{M}_{o}$. This in turn is closely linked to $\mathrm{M}_{w}$. Burton et al. (2004), in agreement with Grünthal and Wahlström (2003) points out that preparation of an earthquake catalogue should logically be on the moment magnitude scale, $\mathrm{M}_{w}$, to enable consistent description of an earthquake size. However, further on they provide reasoning behind supplementing each event with a homogenized surface-wave scale as "....seismic hazard attenuation laws are still more often expressed in terms of $\mathrm{M}_{s}$ than $\mathbf{M}_{w}$ ". Consequently, this catalogue reports all earthquakes on both homogenised $\mathrm{M}_{w}$ and $\mathrm{M}_{s}$ magnitude scales, providing flexibility and choice.

\section{Summary}

A new earthquake catalogue for the instrumental era has been created for the central European and Balkan region bounded by $39^{\circ}-45^{\circ} \mathrm{N}, 19^{\circ}-29^{\circ} \mathrm{E}$. Given limitations of previous catalogues in terms of time intervals covered, magnitude inhomogeneity and completeness, geographical extent and data content, the task was set to derive a new data source that met explicit requirements for this seismic province and define as completely as possible the seismicity of the region during the time interval 1900 to 2004.

Reported magnitudes for all 3681 events have been converted onto homogenized moment magnitude and surfacewave magnitude scales using a selection of carefully chosen magnitude conversion equations. Magnitude conversion hierarchies have been developed to enable consistent conversion from reported $\mathrm{m}_{b}, \mathrm{M}_{s}, \mathrm{M}_{w}$ and $\mathrm{M}_{L}$ magnitude estimates onto these homogenized moment and surface-wave scales. All these steps enable magnitude homogeneity to be retained across the data throughout the geographical region. Data have not been filtered to remove quarry blasts within the catalogued region.

International Seismological Centre data have often been used to derive $\mathrm{m}_{b} \rightarrow \mathrm{M}_{s}$ magnitude regression equations for regions of the world. New region-specific magnitude regression equations have been developed from suitable ISC data to enable conversion from the $\mathrm{m}_{b}$ magnitude scale onto the $\mathrm{M}_{s}$ magnitude scale (Fig. 2).

Catalogue completeness is a major issue of concern for seismologists using earthquake catalogues as a tool to develop seismic hazard analyses. Completeness is strongly governed by data availability, which in turn is linked to geographical region and time interval considered. A number of standard methods have been adopted here to suggest possible limits on magnitude completeness in the catalogue. 
An approximate agreement for a magnitude completeness threshold of $\approx 4.6 \mathrm{M}_{s}$ is suggested by cumulative frequencymagnitude and time-magnitude distributions.

This catalogue will be used in a seismic hazard assessment of Bulgaria and its surrounding region in future work and is available on $\mathrm{CD}$ on request from either author at the Seismic Risk Group.

Acknowledgements. We are grateful to $\mathrm{B}$. Ranguelov and E. Papadimitriou for their constructive comments and valuable information that enabled this paper to be finished. We wish to thank Y. Xu for comments and constructive suggestions during the development of this paper and area of research in general. We are also grateful to S. Sargeant and R. Musson of the British Geological Survey, M. Aspinwall, D. Storchak and J. Harris of the International Seismological Centre, G. Leydecker of the Federal Institute for Geosciences and Natural Resources, Germany, and N. Özel of the Kandilli Observatory and Earthquake Research Center, Turkey for assistance with data acquisition to enable this catalogue to be created. Finally, many thanks to A. Dent of the Geography Department, Office for National Statistics, England for assistance with the manipulation and formatting of a number of key images that are used in this work.

Edited by: S. Tinti

Reviewed by: B. Ranguelov and E. Papadimitriou

\section{References}

Abe, K. and Noguchi, S.: Determination of magnitudes for large shallow earthquakes 1898-1917, Phys. Earth Planet. Interiors, 32, 45-59, 1983a.

Abe, K. and Noguchi, S.: Revision of magnitudes of large shallow earthquakes, 1897-1912, Phys. Earth Planet. Interiors, 33, 1-11, 1983 b.

Alsan, E., Tèzuçan, L., and Båth, M.: An earthquake catalogue for Turkey for the interval 1913-1970, Common Rep. 75 Kandilli Turkey Obs., Seism. Inst. Uppsala, Sweden, 1975.

Ambraseys, N. N.: The Kresna earthquake of 1904 in Bulgaria, Annali di Geofisica, 44(1), 95-117, 2001.

Ambraseys, N. N. and Jackson, J. A.: Faulting associated with historical and recent earthquakes in the Eastern Mediterranean region, Geophys. J. Int. 133, 390-406, 1998.

Baba, A. B., Papadimitiou, E., Papazachos, B. C., Papaioannou, C. A., and Karakostas, B. G.: Unified local magnitude scale for earthquakes of south Balkan area, Pure Appl. Geophys., 157, 765-783, 2000.

Basham, P. and Giardini, D.: Technical guidelines for global seismic hazard assessment, Annali di Geofisica, 36, 15-24, 1993.

Bungum, H., Lindholm, C. D., and Dahle, A.: Long-period ground motions for large European earthquakes, 1905-1992, and comparisons with stochastic predictions, J. Seism., 7, 377-396, 2003.

Burton, P. W., Makropoulos, K. C., McGonigle, R. W., Ritchie, E. A., Main, I. G., Kouskouna, V., and Drakopoulos, J.: Contemporary seismicity in eastern Greece from the Volos network (VOLNET): Fault parameters of major and minor earthquakes, Brit. Geol. Surv. Seismological Series, Report, WL/91/29, 106 pp., 1991.
Burton, P. W., Xu, Y., Qin, C., Tselentis, G.-A., and Sokos, E.: A catalogue of seismicity in Greece and the adjacent areas for the twentieth century, Tectonophysics, 390, 117-127, 2004.

Christoskov, L. and Grigorova, E.: Energetic and space-time characteristics of the destructive earthquakes in Bulgaria after 1900, Geophys. Inst. Rev. (in Bulgarian), 12, 79-107, 1968.

Christoskov, L.: A method for estimating the seismological catalogues representativeness and its application to the central part of the Balkan region (in Bulgarian), Bulg. Geophys. J. (unseen), 8, 66-76, 1982.

Constantinescu, L. and Marza, V. I.: A computer-compiled and computer-oriented catalogue of Romania's earthquakes during a millennium (984-1979), Geophysique, 24(2), 193-234, 1980.

Dimitrov, D. S., Chabalier, J.-B., Ruegg, J.-C., Armijo, R., Meyer, B., and Botev, E.: The 1928 Plovdiv sequence (Bulgaria): fault model constrained from geodetic data and surface breaks, Geophys. J. Int., http://www.ipgp.jussieu.fr/ $\sim$ dechabal/plovdiv/ plovdiv0407.doc, 2004.

Dineva, S., Batllo, J., Mihaylov, D., and van Eck, T.: Source parameters of four strong earthquakes in Bulgaria and Portugal at the beginning of the 20th Century, J. Seism., 6(1), 99-123, 2002.

Engdahl, E. R., van der Hilst, R., and Buland, R.: Global teleseismic earthquake relocation with improved travel times and procedures, Bull. Seism. Soc. Am., 88, 722-743, 1998.

Galanopoulos, A. G.: A catalogue of shocks with $\mathrm{I}_{o} \geq \mathrm{VI}$ or $\mathrm{M} \geq 5$ for the years 1801-1958, Athens, 119 pp., 1960.

Galanopoulos, A. G.: On mapping of seismic activity in Greece, Ann. Di. Geof., 16, 37-100, 1963.

Giardini D. (Ed.): The Global Seismic Hazard Assessment Program (GSHAP) 1992-1999, Annali di Geofisica, 42(6), 9571230, 1999.

Giardini, D. and Basham, P.: The Global Seismic Hazard Assessment Program, Annali di Geofisica, 36, 3-13, 1993.

Glavcheva, R., Botev, B., and Rangelov, B.: Observations and monitoring of the seismicity in Bulgaria. European-Mediterranean Seismological Centre Newsletter, 19, 16 pp., 2003.

Gospodinov, S., Zdravchev, I., Alksandrov, B., Peneva, E. Georgiev, I., Tzenkov, Z., Dimitrov, D., and Pashova, L.: Multidisciplinary investigation of the recent movements between basic tectonic structures on the territory of Southwest part of Bulgaria, http://olimpia.topo.auth.gr/GG2002/ SESSION7/GospodinovBG-Sess7.pdf, 9 pp., 2002.

Grigorova, E. and Grigorov, B.: Epicenters and seismic lineaments in Bulgaria, BAS, Sofia (in Bulgarian with French abstract), 83 pp, 1964.

Grünthal, G. and Wahlström, R.: An $\mathrm{M}_{w}$ based earthquake catalogue for central, northern and northwestern Europe using a hierarchy of magnitude conversions, J. Seismol., 7, 507-531, 2003.

Gutenberg, B. and Richter, C. F.: Frequency of Earthquakes in California, Bull. Seism. Soc. Am., 34, 185-188, 1944.

Gutenberg, B. and Richter, C. F.: Frequency Magnitude and energy of earthquakes, Ann. Di. Geof., 9, 1-15, 1956.

International Seismological Centre, On-line Bulletin, http://www. isc.ac.uk/, Bull. Int. Seis. Cent., Thatcham, United Kingdom, 2001.

Johnston, A. C. and Halchuk, S.: The seismicity database for the Global Seismic Assessment Program, Annali di Geofisica, 36(34), 133-151, 1993.

Karakostas, V., Papadimitriou, E., Gospodinov, D., and Ranguelov, 
B.: Slip distribution of the 1928 Chirpan and Plovdiv main shocks and earthquake triggering, VIth International Conference of SGEM, 119-127, 2006.

Kárník, V.: Seismicity of the European Area, Part 1, 1900-1955, Praha, 362 pp., 1968.

Kárník, V.: Seismicity of the European Area. Part 2, 1801-1900, Praha, 218 pp., 1971.

Koravos, G. Ch., Main, I. G., Tsapanos, T. M., and Musson, R. M. W.: Perceptible earthquakes in the broad Aegean area, Tectonophysics, 371, 175-186, 2003.

Main, I. G.: Earthquakes as critical phenomena: Implications for probabilistic seismic hazard analysis, Bull. Seism. Soc. Am., 85, 1299-1308, 1995.

Makropoulos, K. C.: The statistics of large earthquake magnitude and an evaluation of Greek seismicity, $\mathrm{PhD}$ Thesis, University of Edinburgh, 193 pp., 1978.

Makropoulos, K. C. and Burton, P. W.: A catalogue of seismicity in Greece and adjacent areas, Geophys. J. Roy. Astr. Soc., 65, 741-762, 1981.

Margaris, B. N. and Papazachos, C. B.: Moment-magnitude relations based on strong motion records in Greece, Bull. Seism. Soc. Am., 89, 442-455, 1999.

Meyer, B., Armijo, R., and Dimitrov, D.: Active faulting in SW Bulgaria: possible surface rupture of the 1904 Struma earthquake, Geophys. J. Int., 148, 246-255, 2002.

Meyer, B., Sébrier, M., and Dimitrov, D.: Rare destructive earthquakes in Europe: The 1904 Bulgaria event case, Earth Planet. Sci. Lett., 253, 485-496, 2007.

Musson, R. M. W.: Probabilistic Seismic Hazard Maps for the North Balkan Region. British Geological Survey website, http: //www.bgs.ac.uk/, 18 pp., 1999.

Oncescu, M. C., Marza, V. I, Rizescu, M., and Popa, M.: The Romanian Earthquake Catalogue between 984-1997, in: Vrancea Earthquakes: Tectonics, Hazard and Risk Mitigation, edited by: Wenzel, F., Lungu, D., and Novak, O., Kluwer Academic Publishers, Dordrecht, Netherlands, 43-47, 1999.

Pacheco, J. F. and Sykes, L. R.: Seismic moment catalog of large shallow earthquakes, 1900 to 1989, Bull. Seism. Soc. Am., 82(3), 1306-1349, 1992.

Papazachos, B. C.: Seismicity of the Aegean and surrounding Area, Tectonophysics, 178, 287-308, 1990.

Papazachos, B. C. and Comninakis, P. E.: Geophysical and tectonic features of the Aegean, Arc. J. Geophys. Res., 76, 8517-8533, 1971.

Papazachos, B. C. and Papazachou, C.: The Earthquakes of Greece, Ziti Publications, 304 pp, 1997.

Papazachos, B. C., Kiratzi, A. A., and Karakostas, B. G.: Towards a Homogenous Moment-Magnitude Determination for Earthquakes in Greece and the Surrounding Area, Bull. Seism. Soc. Am., 87(2), 474-483, 1997.

Pavlides, S. and Caputo, R.: Magnitude versus faults' surface parameters: quantitative relationships from the Aegean Region, Tectonophysics, 380, 159-188, 2004.

Perez, O. J.: Revised World Seismicity Catalog (1950-1977) for Strong (Ms $\geq 6$ ) Shallow ( $\leq 70 \mathrm{~km}$ ) Earthquakes, Bull. Seism. Soc. Am., 89(2), 335-341, 1999.

Prochazkova, D., Schenkova, Z., and Kárník, V.: Catalogue of Earthquakes and Atlas of Isoseismals for the Bohemian Massif, the Carpathians and the Rhodope Mts. Progress Report (1974-
1975), Working Group 4.3.3 of the Commission of Academies of Sciences of Socialistic Countries for Planetary Geophysical Research, 102-105, 1977.

Purcaru, G.: The Vrancea, Romania earthquake of 4th March, 1977 - a quite successful prediction, Phys. Earth. Planet. Int., 18, 274287, 1979.

Radu, C.: Catalogue of Strong Earthquakes originated on the Romanian Territory: Part 1 - Before 1901; Part II - 1901-1979 (in Romanian), Cerc. Seism., CFPS, Bucharest (unseen), 723-752, 1979.

Radu, C.: Strong earthquakes occurred on the Romanian territory in the period 1901-1990. (in Romanian), Vitralii (unseen), 3, 1213, 1991.

Ranguelov, B., Rizhikova, S., Shanov, S., Gospodinov, D., and Toteva, T.: The seismic potential for the Kresna-Kroupnik zone SW Bulgaria, in: Reports on Geodesy, 4(49), Warsaw, 237-241, 2000a.

Ranguelov, B., van Eck, T., Papadopoulos, G., Pavlides, S., Shanov, S., and Shenk, V.: Initial data for the magnitude reevaluation of the strong earthquakes during 1904 in Kresna-Kroupnik zone (SW Bulgaria), in: Reports on Geodesy, Warsaw, 4(49), 50-55, 2000b.

Ranguelov, B., Rizhikova, S., and Toteva, T.: The earthquake (M7.8) source zone (South-West Bulgaria), Acad. Publ. House "M. Drinov"(unseen), 279 pp, 2001.

Rezapour, M. and Pearce, R. G.: Bias in Surface-Wave Magnitude $\mathrm{M}_{s}$ due to Inadequate Distance Corrections, Bull. Seism. Soc. Am., 88, 43-61, 1998.

Richter, C. F.: Elementary Seismology, Freeman, 768 pp., 1958.

Rizhikova, S., Toteva, T., and Ranguelov, B.: Seismicity of the Kresna source zone for eighty-year post active period (19091989), in: Reports on Geodesy, Warsaw, 4(49), 56-60, 2000.

Shebalin, N. V., Kárník, V., and Hadzvieski, D. (Eds.): Catalogue of earthquakes of the Balkan region, Parts I-III, UNDP/UNESCO Survey of the seismicity of the Balkan region, Parts I+II, 600 pp., Part III, Atlas, 1974.

Shebalin, N. V., Leydecker, G., Mokrushina, N. G., Tatevossian, R. E., Erteleva, O. O., and Vassilev, V. Yu.: Earthquake Catalogue for Central and Southeastern Europe 342BC-1990AD. Final report to contract ETNU-CT93-0087, 1998.

Sledzinski, J. (Ed.): Reports on Geodesy, Warsaw University of Technology, Warsaw, Poland (unseen), 4(49), 2000.

Sokerova, D., Simeonova, S., Nikolova, S., Solakov, D., and Botev, E.: Geomorphology and Geology, Seismicity and Seismotectonics of the NPP "Kozloduy", Final summary report, Publ. Geophys. Inst.(unseen), 40 pp, 1992.

Stanishkova, I. and Slejko, D.: Some seismotectonic characteristics of Bulgaria, Boll. Geof. Teor. Appl., 33, 187-210, 1991.

Toteva, T., Rizhikova, S., and Ranguelov, B.: Recent seismicity in Kresna region and surroundings, in: Reports on Geodesy, Warsaw, 4(49), 90-98, 2000.

Trifu, C. I. and Radulian, M.: Depth-magnitude catalogue of Vrancea intermediate depth microearthquakes, Rev. Roum. Geophys., 35, 31-45, 1991.

Utsu, T.: Aftershocks and Earthquake Statistics (III) - Analysis of the distribution of Earthquake in Magnitude, Time and Space with Special Consideration to Clustering Characteristics of Earthquake Occurrence (1), J. Faculty of Science, Hokkaido University, Series VII (Geophysics), 3, 5379-394, 1971. 
van Eck, T. and Stoyanov, T.: Seismotectonics and seismic hazard modelling for Southern Bulgaria, Tectonophysics, 262, 77-100, 1996.

Vere-Jones, D.: Stochastic Models for Earthquake Occurrence, J. Roy. Statist. Soc., Series B, 32, 1-62, 1970.

Wells, D. L. and Coppersmith, J. K.: New empirical relationships among magnitude, rupture length, rupture width, rupture area, and surface displacement, Bull. Seism. Soc. Am., 84, 974-1002, 1994.
Willemann, R. J.: Regional Thresholds of the ISC Bulletin, Seismological Res. Lett., 70(3), 313-321, 1999.

Yilmaztürk, A., Bayrak, Y., and Çakir, Ö.: Crustal Seismicity In and Around Turkey, Natural Hazards, 18, 253-267, 1998.

Yilmaztürk, A. and Burton, P. W.: An evaluation of seismic hazard parameters in southern Turkey, J. Seismology, 3, 61-81, 1999.

York, D.: Least squares fitting of a straight line with correlated errors, Earth Planet. Sci. Lett., 5, 320-324, 1969. 